\title{
SHEAR STRENGTH OF HEAT-TREATED SOLID WOOD BONDED WITH POLYVINYL-ACETATE REINFORCED BY NANOWOLLASTONITE
}

\author{
Hamid R. Taghiyari ${ }^{1}$, Ayoub Esmailpour ${ }^{1}$, Stergios Adamopoulos ${ }^{2}$, Kurosh \\ Zereshit $^{1}$, Reza Hosseinpourpia ${ }^{2}$ \\ ${ }^{1}$ Shahid Rajaee Teacher Training University, Tehran, Iran \\ ${ }^{2}$ Linnaeus University, Växjö, Sweden \\ (Received May 20i9)
}

\begin{abstract}
This study investigated the shear strength of heat-treated solid wood of three species (beech, poplar, and fir) bonded with polyvinyl-acetate (PVA) adhesive reinforced by nanowollastonite (NW). Wood specimens were heat-treated at $165^{\circ} \mathrm{C}$ and $185^{\circ} \mathrm{C}$, and then bonded using PVA reinforced by $5 \%$ and $10 \%$ of NW. Shear strength tests parallel to the grain of bonded specimens were performed according to ASTM D143-14 (2014). The results demonstrated that the shear strength was significantly dependent upon the density of the specimens. Heat treatment decreased the shear strength of the bonded specimens considerably. This was attributed to several factors, such as a reduction in polar groups in the cell wall, increased stiffness of the cell wall after heat treatment, and a reduction in the wettability of treated wood. However, NW acted as a reinforcement agent or extender in the complex, and eventually improved the shear bond strength. Moreover, the density functional theory (DFT) proved the bond formation between calcium atoms in the NW and hydroxyl groups of cell wall polymers. The overall results indicated the potential of NW to improve the bonding strength of heat-treated wood.
\end{abstract}

KEYWORDS: Heat treatment, nano-suspensions, polyvinyl-acetate adhesive (PVA), shear bond strength, wollastonite.

\section{INTRODUCTION}

Wood is a renewable raw material for numerous industrial sectors; however, it is susceptible to abiotic and biological degradations. Wood modification is an established, environmentally friendly technology that decreases the hygroscopicity of wood and, consequently, diminishes the moisture-induced deformation processes and abiotic and biotic damages, such as those caused by 
weathering and fungal decay (Hosseinpourpia et al. 2016, Ayata et al. 2017, Behr et al. 2018). Chemical modification, such as acetylation, involves a reaction between a chemical reagent and the reactive parts (mainly hydroxyl groups) of wood components. As a result, covalent bonds are formed and the basic chemistry and properties of the wood's cell wall polymers are changed (Papadopoulos and Hill 2002, 2003, Hill 2006, 2008). Impregnation modification of wood with thermosetting resins, such as melamine-formaldehyde and phenol formaldehyde, alters its material properties, but the chemical structure of the cell wall polymer remains unchanged (Mahnert et al. 2013, Kielmann et al. 2014, Hosseinpourpia and Mai 2016a,b,c). Thermal modification improves wood properties by altering its chemical structure, mainly hemicelluloses (Kato and Cameron 1999, Borrega and Karenlampi 2010, Suchy et al. 2010, Hosseinpourpia et al. 2018). However, this method results in a reduction in the mechanical strength of modified wood, particularly impact bending (Hill 2006). Wood degradation starts at temperatures of approximately $120^{\circ} \mathrm{C}$ (Kollmann and Fengel 1965) with cleavage of the ether linkages of hemicelluloses and the formation of carboxylic acids (Tjeerdsma et al. 1998, Garrote et al. 2001, Tjeerdsma and Militz 2005, Sundqvist et al. 2006). The latter catalyzes the further degradation of polysaccharides (Tjeerdsma et al. 1998), and releases formaldehyde and other aldehydes (Peters et al. 2008, 2009). Lignin is a more stable polymer during thermal degradation when compared to polysaccharides, but its chemical structure alters through the demethoxylation of ether bonds, auto-condensation reactions, and cross-linking (Mahnert et al. 2013, Tjeerdsma et al. 1998, Sivonen et al. 2002, Wikberg and Maaunu 2004, Nuopponen et al. 2005, Hosseinpourpia et al. 2017).

Alterations in the chemical structure of wood due to the thermal modification might affect its gluing and painting ability (Kamdem et al. 2002, Inari et al. 2007, Bastani et al. 2015). It was shown previously that the penetration of a polyvinyl-acetate (PVA) adhesive increased considerably into Scots pine and beech wood treated at $195^{\circ} \mathrm{C}$ (Bastani et al. 2016a). The authors argued that thermal modification creates some free spaces in the wood structure through the cell wall deterioration, like cracking and/or the decomposition of some chemical compounds inside lumens, such as extractives, which results in the development of additional flow pathways for the adhesive.

The thermal conductivity of nanofluids containing dispersed metallic nanoparticles has been widely studied. In general, these nanofluids increase wood's thermal conductivity due to the enhancement of heat transfer (Majidi 2016, Harsini et al. 2017, Sandeep et al. 2017). Metal and mineral nanoparticles and nanofibers have been used to increase the heat-transfer and resistance to fungal deterioration in solid wood and wood-based composites (Mantanis and Papadopoulos 2010, Akhtari et al. 2013, Haghighi et al. 2014, Taghiyari et al. 2014a,b, Soltani et al. 2016).

Wollastonite is a silicate mineral compound $\left(\mathrm{CaSiO}_{3}\right)$ that can be found in many countries including the USA, China, and Iran. A number of studies have investigated the influence of nanowollastonite impregnation on the properties of wood and wood-based composites (Haghighi et al. 2014, Soltani et al. 2016, Schmidt 2006, Maresi et al. 2013, Taghiyari et al. 2013, 2016a, Taghiyari and Moradi Malek 2014, Kumar et al. 2020). The formation of bonds between the nanowollastonite (NW) and wood components resulted in the engagement of hydroxyl groups in wood, eventually improving the dimensional stability. Additionally, its high thermal conductivity coefficient accelerates resin-curing, resulting in an improvement in the wood's physical and mechanical properties. The NW acted as a physical barrier towards the penetration of fire, increasing fire-retardancy in both solid wood and wood-composites. Furthermore, its growthreducing effects on some pathogens, including fungi, improved biological resistance to some wood-deteriorating fungi (Haghighi et al. 2014, Soltani et al. 2016, Schmidt 2006, Maresi et al. 2013, Taghiyari et al. 2013, 2016a, Taghiyari and Moradi Malek 2014). 
As the use of wollastonite nanomaterials has become more popular to improve the technological properties of wood and wood-based composites during the last few years, it is important to expand the knowledge of their influence on the bonding behavior of solid wood adhesives. Therefore, the present study aims to investigate the tensile shear strength of untreated and heat-treated beech, poplar, and fir wood bonded with a nanowollastonite reinforced PVA adhesive.

\section{MATERIAL AND METHODS}

\section{Material}

Specimen preparation

Beech (Fagus orientalis L. collected from Chalous, Iran), poplar (Populus nigra L.; collected from Chalous, Iran), and Silver fir (Abies alba Mill. imported from Russia) were selected as the test wood species based on their importance in various industrial applications in Iran. Ninety specimens, free from knots, cracks, and other physical or fungal damages were prepared for each wood species. In total, 270 specimens were prepared for all three wood species, as shown in Fig. 1.

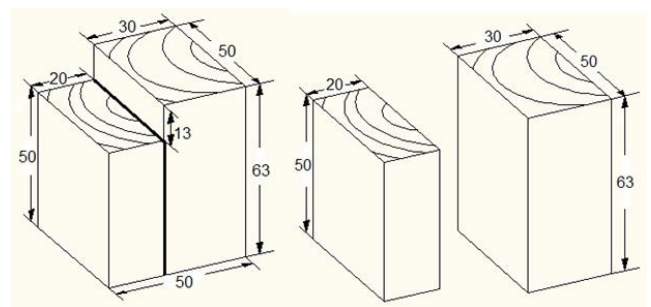

Fig. 1: Details of sample preparation for the shear strength testing. From right to the left: dimensions of the large and small pieces to be glued and final sample size showing a thicker glue line (dimensions in $\mathrm{mm}$ ).

The specimens were randomly divided into three treatments, including untreated (UT), and heat-treated at $165^{\circ} \mathrm{C}(\mathrm{HT}-165)$ and $185^{\circ} \mathrm{C}(\mathrm{HT}-185)$. Then, the specimens were divided into three sub-groups for gluing with polyvinyl acetate adhesive (PVA), and with polyvinyl acetate containing 5\% (PVA-5NW) and 10\% nanowollastonite (PVA-10NW). The PVA adhesive was purchased from Shomal Resin \& Adhesive Co. (Tehran, Iran), with a viscosity of $500 \pm 20$, and $50 \pm 5 \%$ solid content. Ten specimens were used for each treatment condition.

\section{Heat treatment process}

Specimens of each heat-treatment temperature were randomly arranged in an oven and heated for $5 \mathrm{~h}$ at $165^{\circ} \mathrm{C}$ and at $185^{\circ} \mathrm{C}$ for HT-165 and HT- 185 treatments, respectively. The treatment initiated when the internal temperature of the oven reached the target temperatures $\left(165\right.$ or $\left.185^{\circ} \mathrm{C}\right)$. The specimens were weighed both before and after the heat treatment by a digital scale (with $0.0001 \mathrm{~g}$ precision) to assess the mass changes during the process.

\section{Aqueous NW addition}

Aqueous NW gel with $70 \%$ to $75 \%$ solid content and a size range of 30 to $110 \mathrm{~nm}$ was purchased from Lotfali-Zade Mehrabadi Manufacturing Company of Mineral and Industrial Products, Tehran, Iran. The compound contents of NW are summarized in Tab. 1. 
Tab. 1: Compounds and formulations of the wollastonite nanosuspension (Taghiyari et al. 2016a, 2014ab, Esmailpour et al. 2019ab).

\begin{tabular}{|c|c|}
\hline Nanowollastonite compounds & Mixing ratio by mass (\% wt.) \\
\hline $\mathrm{CaO}$ & 39.77 \\
\hline $\mathrm{SiO}_{2}$ & 46.96 \\
\hline $\mathrm{Al}_{2} \mathrm{O}_{3}$ & 3.95 \\
\hline $\mathrm{Fe}_{2} \mathrm{O}_{3}$ & 2.79 \\
\hline $\mathrm{TiO}_{2}$ & 0.22 \\
\hline $\mathrm{K}_{2} \mathrm{O}$ & 0.04 \\
\hline $\mathrm{MgO}$ & 1.39 \\
\hline $\mathrm{Na}_{2} \mathrm{O}$ & 0.16 \\
\hline $\mathrm{SO}_{3}$ & 0.05 \\
\hline $\mathrm{Water}^{2}$ & 4.67 \\
\hline
\end{tabular}

Based on the dry weight of PVA, 5\% and 10\% of NW gel were added to produce PVA$5 \mathrm{NW}$ and PVA-10NW gluing systems, respectively. The mixtures were blended for 30 min with a magnetic stirrer for an even dispersion of NW.

\section{Methods}

Shear strength parallel to grain

After the heat treatments, the samples were prepared for their determination of shear strength parallel to grain. Dimensions of the specimens and testing method were performed according to the ASTM D143-14 (2014) standard. Two pieces (small and large) were prepared according to the standard from the UT, HT-165, and HT-185 specimen collectives and subsequently bonded with PVA, PVA-5NW, and PVA-10NW gluing systems (Fig. 1). Then, the glued samples were stored at room conditions $\left(25 \pm 2^{\circ} \mathrm{C}, 40 \pm 3 \% \mathrm{RH}\right)$ for eight weeks to complete the polymerization of the adhesive. Determination of shear strength was carried out using an Instron 4486 universal testing machine (Norwood, MA, USA). The loading was applied continuously throughout the test at a rate of motion of $0.6 \mathrm{~mm} \cdot \mathrm{min}^{-1}$. The testing for each specimen was discontinued after the first sudden drop of the loading force.

\section{Theoretical analysis}

Density functional theory (DFT) was carried out with OpenMX 3.6 package (Ozaki Group, Tokyo, Japan) to study the adsorption of NW on the cellulose surface (Perdew et al. 1996, Grimme 2006). The generalized gradient approximation (GGA) function with the Perdew-Burke-Ernzerhof (PBE) correction was used to describe the exchange-correlation energy functional (Perdew et al. 1996). The Van der Waals (vdW) interactions were included in the density functional theory (DFT) approach proposed by Grimme (2006).

\section{Statistical analysis}

Statistical analysis was conducted using the SPSS software program, version 18 (Chicago, USA). A one-way analysis of variance (ANOVA) was performed to discern significant differences at a $95 \%$ confidence level among the different treatments, as described previously (Hosseinpourpia et al. 2019a,b). Fitted-line and surface plots were made using the Minitab software, version 16.2.2 (Minitab Inc., State College, PA, USA). 


\section{RESULTS AND DISCUSSION}

The mean mass loss of the heat-treated samples increased with increasing temperature (Fig. 2), due to the higher degradation of wood polysaccharides, mainly hemicelluloses, and the evaporation of extractives (Zaman et al. 2000, Alen et al. 2002, Mahnert et al. 2013, Hosseinpourpia et al. 2016c).

The highest weight loss was $14.8 \%$, which was obtained for the HT-185 beech specimens. This might have been attributed to the higher density and the higher polymer compounds contained in beech as compared to poplar and fir. The density of unheated beech was measured at $0.7 \mathrm{~g} \cdot \mathrm{cm}^{-3}$ in comparison to those of poplar $\left(0.4 \mathrm{~g} \cdot \mathrm{cm}^{-3}\right)$ and fir $\left(0.38 \mathrm{~g} \cdot \mathrm{cm}^{-3}\right)$.

The shear strength results of the untreated specimens showed that the highest and the lowest values were found for beech and fir at 8.3 MPa and 4.8 MPa, respectively (Fig. 3). Poplar exhibited greater shear strength $(6.7 \mathrm{MPa})$ than fir $(4.8 \mathrm{MPa})$. The transversal permeability of poplar and fir were reported as 0.0028 and $0.0004 \times 10-13 \mathrm{~m}^{3} \cdot \mathrm{m}^{-1}$, respectively (Taghiyari et al. 2016b). The higher permeability may have provided better penetration of the PVA adhesive into the wood structure, which resulted in the greater shear strength of poplar as compared to fir. However, the adhesive penetration needs to be measured and analyzed in further studies for a final conclusion on the possible correlation between the shear strength of adhesives and the permeability of untreated wood.

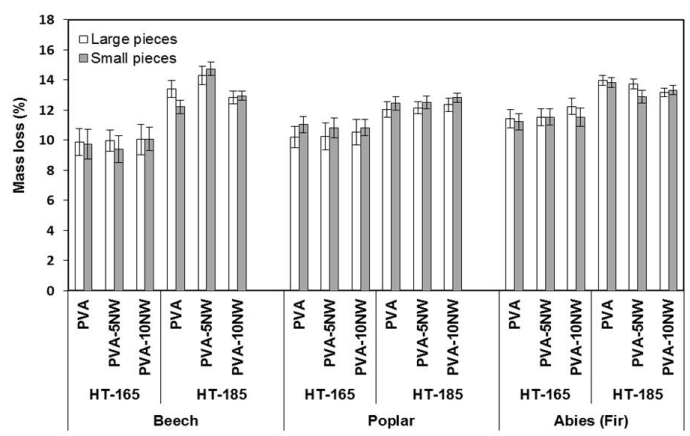

Fig. 2: Mass loss (\%) of beech, poplar, and fir samples treated at $165^{\circ} \mathrm{C}(H T-165)$ and $185^{\circ} \mathrm{C}$ (HT-185).

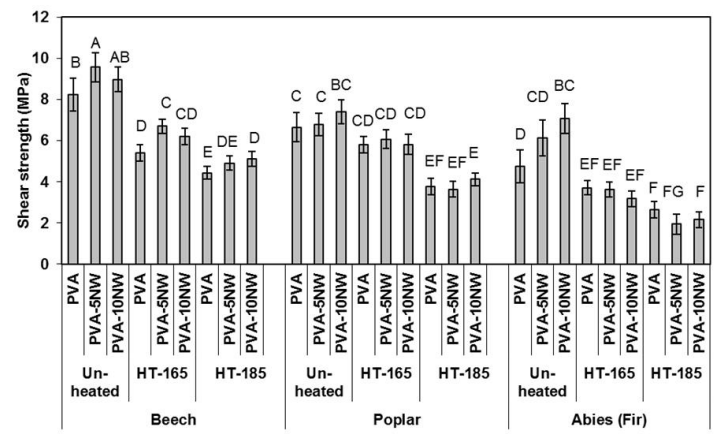

Fig. 3: Shear strength of untreated and heat-treated beech, poplar, and fir bonded with PVA reinforced with NW. The standard deviation was based on the entire population, and the statistical differences were tested with ANOVA and a Duncan test. The labeled values were statistically equal at an error probability of $\alpha=0.05$. 
Heat treatment reduced the shear strength for all three wood species; a higher temperature resulted in greater shear strength loss (Fig. 3). The highest and lowest losses in shear strength as a result of heat treatment were observed in HT-185 beech with PVA resin (86\%) and poplar HT-165 (79\%) with 5\% NW content, respectively. This was in accordance to Sahin Kol and co-workers (2009) and Bastani and colleagues (2016b), who found that the bonding strength was reduced in heat-treated wood samples. The shear strength reduction of heat-treated wood can be attributed to: (a) a reduction of polar groups in the cell wall due to the degradation of amorphous polysaccharides by the heat treatment, resulting in less sites available for bonding (Inari et al. 2007, Goli et al. 2014), (b) an increased stiffness of the cell wall after heat treatment (Altgen et al. 2016), which results in a reduction of internal surfaces for chemical bonding or mechanical interlocking of adhesives (Bastani et al. 2015); and (c) a reduction in wettability that may hamper the proper curing of water-based adhesives such as PVA (Bastani et al. 2015). The formation of micro-cracks and checks due to the heat treatment at temperatures above $180^{\circ} \mathrm{C}$ might also contribute to a declined shear strength of heat-treated wood (Taghiyari and Moradi Malek 2014).

The addition of NW to PVA adhesive resulted in an improvement of shear strength for the untreated samples of all three species (Fig. 3). This positive effect could be partly attributed to the formation of bonds between the wood cell compounds and NW. By means of density functional theory, Taghiyari and co-workers (2016) calculated an optimal adsorption distance and adsorption energy for NW of $1.7 \AA$ and $-6.6 \mathrm{eV}$, respectively. In fact, this rather large adsorption energy obviously indicated a formation of additional bonds between the calcium atoms of NW and the oxygen atoms of hydroxyl groups of the wood cell wall polymers (Fig. 4).

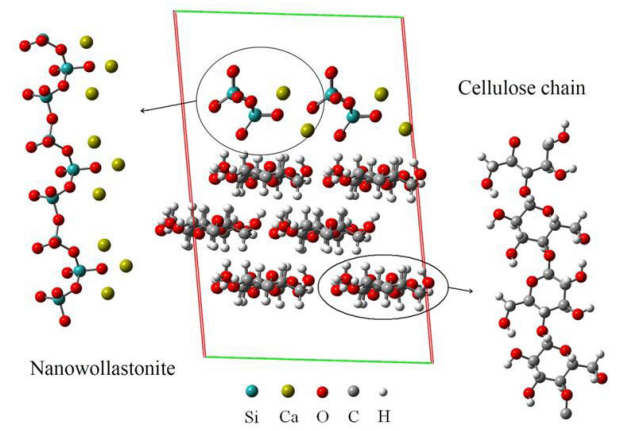

Fig. 4: Schematic representation of bond formation between calcium atoms of $N W$ and oxygen atoms of cell wall cellulose chains.

This could eventually contribute to higher shear strength of samples bonded with PVA-NW systems than with PVA alone. The formation of similar bonds was the main cause of an increased thermal conductivity coefficient and of improved physical and mechanical properties of medium-density fiberboard, in which the resin was treated with NW before being sprayed on the fibers (Taghiyari et al. 2013, 2014a,b). The hardness of wollastonite is relatively high, around 4.5 to 5 based on Mohs scale of mineral hardness. This may have enabled NW fibers to act as reinforcement filler in the glue layer between the two wood pieces, and eventually have fortified their bonding. In the heat-treated samples, the addition of NW to PVA adhesive improved the shear strength of beech specimens. However, it did not change the shear strength of the poplar samples. In the case of fir specimens, the addition of NW to PVA adhesive even slightly reduced the shear strength. This might have been attributed to an increased availability of bonding sites 
in beech wood due to the higher density, even after heat-treatment, when compared to poplar and fir.

Macroscopic observation of the tested specimens revealed that most of the failures, in sole PVA adhesive, occurred along the glue line rather than in the wood structure. This was true for both treated and untreated wood samples. However, reinforcement of the PVA with NW provided stronger bonds than solely PVA, which caused the failure in the wood structure (Fig. 5).

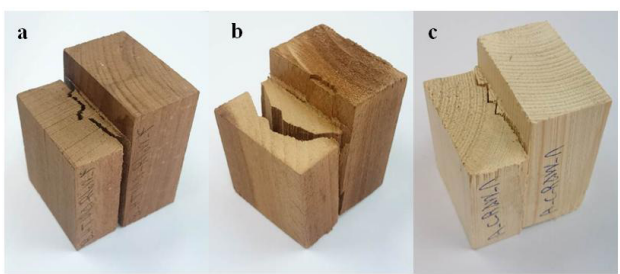

Fig. 5: Wood failures of heat-treated beech at $185^{\circ} \mathrm{C}$ bonded with PVA-10NW (a), heat-treated poplar at $185^{\circ} \mathrm{C}$ bonded with PVA-5NW(b), and control fir bonded with.

A long service life of glued wood elements requires tolerant adhesives under different temperature and humidity conditions, and therefore, further studies should be carried out to explore such effects on the performance of NW-reinforced adhesives.

\section{CONCLUSIONS}

(1) For all of the wood species, the shear strength of the heat-treated samples bonded with PVA adhesive were significantly lower than that of the untreated ones, at a $95 \%$ statistical confidence level.

(2) The shear strength of untreated beech, poplar, and fir specimens bonded with PVA adhesive was improved by the addition of NW. It was suggested that NW acted as a reinforcement agent in the adhesive.

(3) Although the shear strength of the heat-treated beech increased by adding NW to PVA adhesive, a clear trend was not observed in shear strength of heat-treated poplar and fir specimens by adding NW.

\section{ACKNOWLEDGMENTS}

The first author acknowledges the constant scientific support of his mentor, Mr. Jack Norton (Retired, Horticulture and Forestry Science, Queensland Department of Agriculture, Forestry and Fisheries, Brisbane, Australia). Technical drawing by Engr. Afrooz Ghiyasvand is also appreciated.

\section{REFERENCES}

1. Akhtari, M., Taghiyari, H.R., Ghorbani Kokandeh, M., 2013: Effect of some metal nanoparticles on the spectroscopy analysis of Paulownia wood exposed to white-rot fungus. European Journal of Wood and Wood Products 71(2): 283-285. 
2. Alen, R., Kotilainen, R., Zaman, A., 2002: Thermochemical behavior of Norway spruce (Picea abies) at $180-225^{\circ} \mathrm{C}$. Wood Science and Technology 36(2): 163-171.

3. Altgen, M., Hofmann, T., Militz, H., 2016: Wood moisture content during the thermal modification process affects the improvement in hygroscopicity of Scots pine sapwood. Wood Science and Technology 50(6): 1181-1195.

4. Ayata, U., Akcay, C., Esteves, B., 2017: Determination of decay resistance against Pleurotus ostreatus and Coniophora puteana fungus of heat-treated Scotch pine, oak and beech wood species. Maderas: Ciencia y tecnologia 19: 309-316.

5. ASTM D143-14, 2014: Standard test methods for small clear specimens of timber.

6. Bastani, A., Adamopoulos, S., Militz, H., 2015: Effect of open assembly time and equilibrium moisture content on the penetration of polyurethane adhesive into thermally modified wood. Journal of Adhesion 93(7): 575-583.

7. Bastani, A., Adamopoulos, S., Koddenberg, T., Militz, H., 2016a: Study of adhesive bondlines in modified wood with fluorescence microscopy and X-ray micro-computed tomography. International Journal of Adhesion and Adhesives 68: 351-358.

8. Bastani, A., Adamopoulos, S., Militz, H., 2016b: Shear strength of furfurylated, N-methylol melamine and thermally modified wood bonded with three conventional adhesives. Wood Material Science \& Engineering 12(4): 236-241.

9. Behr, G., Bollmus, S., Gellerich, A., Militz, H., 2018: Improvement of mechanical properties of thermally modified hardwood through melamine treatment. Wood Material Science \& Engineering 13(5): 262-270.

10. Borrega, M., Karenlampi, P.P., 2010: Hygroscopicity of heat-treated Norway spruce (Picea abies) wood. European Journal of Wood and Wood Products 68(2): 233-235.

11. Esmailpour, A., Taghiyari H. R., Majidi Najafabadi, R., Kalantari, A., Papadopoulos, A. N., 2019a: Fluid flow in cotton textile: Effects of wollastonite nanosuspension and Aspergillus niger fungus. Processes 7(12): 901..

12. Esmailpour, A., Taghiyari, H. R., Majidi, R., Morrell, J. J., Mohammad-Panah, B., 2019b: Nano-wollastonite to improve fire retardancy in medium-density fiberboard (MDF) made from wood fibers and camel-thorn. Wood Material Science \& Engineering, published online: doi 10.1080/17480272.2019.1641838.

13. Garrote, G., Domínguez, H., Parajó, J. C., 2001: Study on the deacetylation of hemicelluloses during the hydrothermal processing of Eucalyptus wood. Holz als Roh- und Werkstoff 59(1-2): 53-59.

14. Goli, G., Cremonini, C., Negro, F., Zanuttini, R., Fioravanti, M., 2014: Physicalmechanical properties and bonding quality of heat treated poplar (I-214) and ceiba plywood. iForest 8: 687-692.

15. Grimme, S., 2006: Semiempirical GGA-type density functional constructed with a longrange dispersion correction. Journal of Computational Chemistry 27(15): 1787-1799.

16. Harsini, I., Matalkah, F., Soroushian, P., Balachandra, A.M., 2017: Robust, carbon nanotube/polymer nanolayered composites with enhanced ductility and strength. Journal of Nanomaterials \& Molecular Nanotechnology 6(3): 1-6.

17. Haghighi, A.P., Taghiyari, H.R., Karimi, A.N., 2014: Fire-retarding properties of nanowollastonite in solid wood. Philippine Agricultural Scientist 97(1): 52-59.

18. Hill, C.A.S., 2006: Wood modification chemical, thermal and other processes. John Wiley and Sons, Ltd., Chichester, West Sussex, England, 238 pp.

19. Hill, C.A.S., 2008: The reduction in the fibre saturation point of wood due to chemical modification using anhydride reagents: A reappraisal. Holzforschung 62(4): 423-428. 
20. Hosseinpourpia, R., Adamopoulos, S., Mai, C., 2016: Dynamic vapour sorption of wood and holocellulose modified with thermosetting resins. Wood Science and Technology 50(1): 165-178.

21. Hosseinpourpia, R., Mai, C., 2016a: Mode of action of brown rot decay resistance of acetylated wood: Resistance to Fenton's reagent. Wood Science and Technology 50: 413-426.

22. Hosseinpourpia, R., Mai, C., 2016b: Mode of action of brown rot decay resistance in phenol-formaldehyde-modified wood: Resistance to Fenton's reagent. Holzforschung 70(3): 253-259.

23. Hosseinpourpia, R., Mai, C., 2016c: Mode of action of brown rot decay resistance of thermally modified wood: Resistance to Fenton's reagent. Holzforschung 70(7): 691-697.

24. Hosseinpourpia, R., Adamopoulos, S., Holstein, N., Mai, C., 2017: Dynamic vapour sorption and water-related properties of thermally modified Scots pine (Pinus sylvestris L.) wood pre-treated with proton acid. Polymer Degradation and Stability 138: 161-168.

25. Hosseinpourpia, R., Adamopoulos, S., Mai, C., 2018: Effects of acid pre-treatments on the swelling and vapor sorption of thermally modified Scots pine (Pinus sylvestris L.) wood. BioResources 13(1): 331-345.

26. Hosseinpourpia, R., Adamopoulos, S., Parsland, C., 2019a: Utilization of different tall oils for improving the water resistance of cellulosic fibers. Applied Polymer Science 136(13): 47303.

27. Hosseinpourpia, R., Adamopoulos, S., Mai, C., Taghiyari, H.R., 2019b: Properties of medium-density fibreboards bonded with dextrin-based wood adhesive. Wood Research 64(2): 185-194.

28. Inari, G.N., Petrissans, M., Gerardin, P. 2007: Chemical reactivity of heat-treated wood. Wood Science and Technology 41(2): 157-168.

29. Kato, K.L., Cameron, R.E., 1999: A review of the relationship between thermallyaccelerated ageing of paper and hornification. Cellulose 6(1): 23-40.

30. Kamdem, D.P., Pizzi, A., Jermannaud, A., 2002: Durability of heat-treated wood. Holz als Roh- und Werkstoff 60(1): 1-6.

31. Kielmann, B.C., Adamopoulos, S., Militz, H., Mai, C., 2014: Decay resistance of ash, beech and maple wood modified with $\mathrm{N}$-methylol melamine and a metal complex dye. International Biodeterioration \& Biodegradation 89: 110-114.

32. Kollmann, F., Fengel, D., 1965: Änderungen der chemischen Zusammensetzung von Holz durch thermische Behandlung (Changes in the chemical composition of wood by thermal treatment). Holz als Roh- und Werkstoff 23(12): 461-468.

33. Kumar, A., Jyske, T., Möttänen, V., 2020: Properties of injection molded biocomposities reinforced with wood particles of short-rotation aspen and willow. Polymers 12(2): 257.

34. Mahnert, K.C., Adamopoulos, S., Koch, G., Militz, H., 2013: Topochemistry of heattreated and N-methylol melamine modified wood of Koto (Pterygota macrocarpa K. Schum.) and Limba (Terminalia superba Engl. et Diels). Holzforschung 67(2): 137-146.

35. Majidi, R., 2016: Electronic properties of graphyne nanotubes filled with small fullerenes: A density functional theory study. Journal of Computational Electronics 15(4): 1263-1268.

36. Mantanis, G. I., Papadopoulos, A. N., 2010: Reducing the thickness swelling of wood based panels by applying a nanotechnology compound. European Journal of Wood and Wood Products 68(2): 237-239.

37. Maresi, G., Oliveira Longa, C.M., Turchetti, T., 2013: Brown rot on nuts of Castanea sativa Mill: An emerging disease and its causal agent. iForest 6: 294-301. 
38. Nuopponen, M., Vuorinen, T., Jämsä, S., Viitaniemi, P., 2005: Thermal modifications in softwood studied by FT-IR and UV resonance Raman spectroscopies. Journal of Wood Chemistry and Technology 24(1): 13-26.

39. Papadopoulos, A.N., Hill, C.A.S., 2002: The biological effectiveness of wood modified with linear chain carboxylic acid anhydrides against Coniophora puteana. Holz als Roh- und Werkstoff 60(5): 329-332.

40. Papadopoulos, A.N., Hill, C.A.S., 2003: The sorption of water vapour by anhydride modified softwood. Wood Science and Technology 37(3-4): 221-231.

41. Perdew, J.P., Burke, K., Ernzerhof, M., 1996: Generalized gradient approximation made simple. Physical Review Letters 77(18): 3865-3868.

42. Peters, J., Fischer, K., Fischer, S., 2008: Characterization of emissions of thermally modified wood and their reduction by chemical treatment. BioResources 3(2): 491-502.

43. Peters, J., Pfriem, A., Horbens, M., Fischer, S., Wagenführ, A., 2009: Emissions from thermally modified beech wood, their reduction by solvent extraction and fungicidal effect of the organic solvent extracts. Wood Material Science \& Engineering 4(1-2): 61-66.

44. Sahin Kol, H., Özbay, G., Altun, S., 2009: Shear strength of heat-treated tali (Erythrophleum ivorense) and iroko (Chlorophora excelsa) woods, bonded with various adhesives. BioResources 4(4): 1545-1554.

45. Sandeep, N., Sulochana, C., Kumar, B.R., 2017: Flow and heat transfer in MHD dusty nanofluid past a stretching/shrinking surface with non-uniform heat source/sink. Walailak Journal of Science and Technology 14(2): 117-140.

46. Schmidt, O., 2006: Wood and tree fungi: Biology, bamage, protection, and use. SpringerVerlag Berlin Heidelberg, Berlin, 334 pp.

47. Sivonen, H., Maunum, S.L., Sundholm, F., Jämsä, S., Viitaniemi, P., 2002: Magnetic resonance studies of thermally modified wood. Holzforschung 56(6): 648-654.

48. Soltani, A., Hosseinpourpia, R., Adamopoulos, S., Taghiyari, H.R., Ghaffari, E., 2016: Effects of heat-treatment and nano-wollastonite impregnation on fire properties of solid wood. BioResources 11(4): 8953-8967.

49. Suchy, M., Kontturi, E., Vuorinen, T., 2010: Impact of drying on wood ultrastructure: Similarities in cell wall alteration between native wood and isolated wood-based fibers. Biomacromolecules 11(8): 2161-2168.

50. Sundqvist, B., Karlsson, O., Westermark, U., 2006: Determination of formic-acid and acetic acid concentrations formed during hydrothermal treatment of birch wood and its relation to colour, strength and hardness. Wood Science and Technology 40(7): 549-561.

51. Taghiyari, H.R., Mobini, K., Sarvari Samadi, Y., Doosti, Z., Karimi, F., Asghari, M., Jahangiri, A., Nouri, P., 2013: Effects of nano-wollastonite on thermal conductivity coefficient of medium-density fiberboard. Journal of Nanomaterials \& Molecular Nanotechnology 2(1): 1-5.

52. Taghiyari, H.R., Bari, E., Schmidt, O., Tajick Ghanbary, M. A., Karimi, A., Tahir, P.M. D., 2014a: Effects of nanowollastonite on biological resistance of particleboard made from wood chips and chicken feather against Antrodia vaillantii. International Biodeterioration \& Biodegradation 90: 93-98.

53. Taghiyari, H.R., Ghorbanali, M., Tahir, P.M.D., 2014b: Effects of the improvement in thermal conductivity coefficient by nano-wollastonite on physical and mechanical properties in medium-density fiberboard (MDF). BioResources 9(3): 4138-4149.

54. Taghiyari, H.R., Moradi Malek, B., 2014: Effect of heat treatment on longitudinal gas and liquid permeability of circular and square-shaped native hardwood specimens. Heat and Mass Transfer 50(8): 1125-1136. 
55. Taghiyari, H.R., Majidi, R., Jahangiri, A., 2016a: Adsorption of nanowollastonite on cellulose surface: Effects on physical and mechanical properties of medium-density fiberboard (MDF). Cerne 22(2): 215-222.

56. Taghiyari, H.R., Esmailpour, A., Zolfaghari, H., 2016b: Effects of nanosilver on sound absorption coefficients in solid wood species. IET Nanobiotechnology 10(3): 147-153.

57. Tjeerdsma, B.F., Boonstra, M., Pizzi, A., Tekely, P., Militz, H., 1998: Characterization of thermally modified wood: Molecular reasons for wood performance improvement. Holz als Roh- und Werkstoff 56(3): 149-153.

58. Tjeerdsma, B.F., Militz, H., 2005: Chemical changes in hydrothermal treated wood: FTIR analysis of combined hydrothermal and dry heat-treated wood. Holz als Roh- und Werkstoff 63(2): 102-111.

59. Wikberg, H., Maaunu, L.S., 2004: Characterization of thermally modified hard- and softwoods by 13C CPMAS NMR. Carbohydrate Polymer 58(4): 461-466.

60. Zaman, A., Alén, R., Kotilainen, R., 2000: Thermal behavior of scots pine (Pinus sylvestris) and silver birch (Betula pendula) at $200^{\circ} \mathrm{C}-230^{\circ} \mathrm{C}$. Wood and Fiber Science 32(2): 138-143.

Hamid Reza Taghiyari

Shahid Rajaee Teacher Training University

Faculty of Materials Engineering \& New Technologies

Wood Science and Technology Department

TEHRAN

IRAN

Ayoub Esmailpour

Shahid Rajaee Teacher Training University

Department of Physics

Faculty of Sciences

TEHRAN

IRAN

Stergios Adamopoulos

LinNAEUs University

Department of Forestry and Wood Technology

LÜCKLigs Plats I

35I95 VÄxנÖ

SWEDEN

Kurosh Zereshi

Shahid Rajaee Teacher Training University

Faculty of Materials Engineering \& New Technologies

Wood Science and Technology Department

TeHran

IRAN 


\author{
*Reza Hosseinpourpia \\ LinNaEus University \\ Department of Forestry and Wood Technology \\ Lückligs Plats I \\ 35195 V̈̈xJÖ \\ SWEDEN \\ *Corresponding author: reza.hosseinpourpia@lnu.se
}

